\title{
No Evidence for Contagious Yawning in Lemurs
}

2 Rachna B. Reddy ${ }^{1,2}$, , Christopher Krupenye ${ }^{1}$, Evan L. MacLean ${ }^{1,3}$, \& Brian Hare ${ }^{1,4}$

3

$4{ }^{1}$ Department of Evolutionary Anthropology, Duke University, Durham, NC, United States

$5 \quad{ }^{2}$ Department of Anthropology, University of Michigan, Ann Arbor, MI, United States

$6{ }^{3}$ School of Anthropology, University of Arizona, Tucson, AZ, United States

$7{ }^{4}$ Center for Cognitive Neuroscience, Duke University, Durham, NC, United States

8

$9 *$ Address for correspondence

10 Rachna B. Reddy

11 rachnare@umich.edu

12 phone: (586) 944-4785

13 fax: (734) 763-6077

14 Department of Anthropology, University of Michigan

15101 West Hall, 1085 S. University Ave.

16 Ann Arbor, MI 48109

17

Keywords: contagious yawning, lemurs, strepsirhine, emotional contagion

Acknowledgements

This project would not have been possible without the help of the staff at the Duke Lemur

21 Center, especially Dr. Erin Ehmke, David Brewer, Julie McKinney, and Meg Dye. We would

22 also like to thank Joel Bray, Ben Finkel, Leah Kaiser, Laura Lewis, Jeremy Clift, Sruti

23 Pisharody, and Seraphina Wong for their help with stimuli and data collection and coding. We

24 would also like to thank Dr. Anne Pusey and Dr. Tanya Chartrand for their helpful feedback in

25 earlier stages of this project, Aaron Sandel for his comments on the manuscript and two

26 anonymous reviewers for their feedback. This research was supported by a grant from the

27 Undergraduate Research Support office at Duke University and a Molly H. Glander Student 
Research Grant from the Duke Lemur Center. RBR and CK were supported by NSF GRFP

DGE-1256260 and DGE-1106401 respectively.

\section{Introduction}

Yawning is an activity common to most vertebrates (Baenninger 1997; Smith 1999;

Gallup 2011) yet its physiological and social functions are still debated. For instance, yawning is purported to prevent respiratory infections and to increase oxygen levels in the blood and brain (Baenninger 1997; Smith 1999; Gallup 2011). In some species, yawns also convey important social or emotional information. A yawn might be given, for example, by a male baboon (Papio cynocephalus) during a threatening dominance display (Altmann 1967), by a captive chimpanzee who has just heard social commotion among her neighbors (Baker \& Aureli 1997) or by a pet dog who is anxious when separated from his owner (Lund \& Jorgensen 1999). Animals may also produce different types of yawns in different contexts. For example, after social conflicts, gelada monkey males often vocalize and then yawn, showing their canines, while female geladas yawn when affiliatively lip-smacking and grooming others (Leone et al. 2014).

Sometimes, however, yawns appear to serve no clear physiological or social function. In these cases, for many species, including those described above, yawns that occur in a relaxed context spread contagiously from individual to individual (Palagi et al. 2009). In humans, yawn contagion is so powerful that people yawn when watching videos of others yawning, when reading about yawning, or when being instructed to think about yawning (Provine 1986). Such non-conscious contagion has been linked to a basic level of empathy (de Waal et al. 2008). The connection to empathy is supported by evidence in humans: subjects who yawn in response to videos of others yawning have fewer schizotypical personality traits and exhibit better perspective-taking skills (Platek et al. 2003). In addition, contagious effects are more powerful among individuals who share social bonds. For instance, humans are more likely to yawn in 
52 response to the yawns of friends and family than acquaintances (Norscia \& Palagi 2011). Given

53 its connection to empathy and sociality, comparative data on contagious yawning may yield

54 insights into social and cognitive evolution.

55 It is important to note that while species from birds, to fish, to snakes produce long, 56 gaping mouth movements that we identify as yawns, it is unclear whether those movements 57 represent the same physiological processes across taxa (Baenninger 1997; Smith 1999). For 58 instance, among mammals, carnivores seem to yawn more frequently than herbivores 59 (Baenninger 1997). Although yawning may serve different functions across species, contagious 60 yawning is nevertheless found in a wide range of species. Observational studies have found contagious yawning in taxa as diverse as birds and 62 bonobos. In captivity, budgerigars, which form cohesive flocks in the wild, are observed to yawn 63 and stretch after conspecifics have yawned and stretched (Miller et al. 2012). Wolves also 64 contagiously yawn, doing so more often if they share a close social bond with the initial yawner 65 (Romero et al. 2014). Among primates, captive bonobos and geladas are more likely to yawn 66 after conspecifics do, particularly if those conspecifics are kin or preferred social partners (Palagi

67 68 et al. 2009; Demuru \& Palagi 2012; Palagi et al. 2014).

Contagious yawning can also be induced experimentally. Both chimpanzees and stumptail macaques yawn when shown videos of yawning conspecifics (Anderson et al. 2004; Paulkner and Anderson 2006; Amici et al. 2014). Importantly, authors noted that these stumptail macaques also displayed nervous behaviors while yawning, suggesting that yawns produced could have been motivated by social stress, so it is unclear whether these yawns were induced by empathy-like capacities (Paulkner and Anderson 2006). In a similar video-playback experiment, 
74

75

76

77

78

79

80

81

82

83

84

85

86

87

88

89

90

91

92

93

94

95

96

chimpanzees were more likely to yawn after watching footage of a yawning groupmate than a yawning stranger (Campbell \& deWaal 2011).

Contagious yawning is not only induced by conspecifics. Captive chimpanzees with human caretakers are more likely to yawn in response to a familiar chimpanzee or human than to an unfamiliar chimpanzee (Campbell \& DeWaal 2014). Dogs may yawn when watching a human experimenter yawn in person (Joly-Mascheroni et al. 2008) and do so more often when the human is familiar (Romero et al. 2013: although see Harr et al. 2009; O’Hara \& Reeve 2011). These interspecific results further emphasize the possibility that emotional bonds influence contagious behavior since dogs may be closely bonded to their human owners and captive apes to their human caretakers.

Understanding how and when such rudimentary empathetic capabilities evolved is key to understanding the evolution of complex social cognition, as both empathy and cognition are entwined with the evolution of sociality (Seyfarth \& Cheney 2013). The comparative method affords a powerful approach for answering questions about how, when, and why particular cognitive capabilities have evolved (MacLean et al. 2012; MacLean et al. 2014). This approach requires data from broad phylogenetic samples in order to estimate the evolutionary origins of particular traits. Among our closest relatives, nonhuman primates, only haplorhines have been the focus of research on contagious yawning. No study has examined whether contagious yawning occurs in strepsirhines - the other major primate lineage including lemurs, lorises, galagos and pottos. Therefore, comparative data from strepsirrhines will bear importantly on whether contagious yawning is common to all primates or unique to the haplorhine lineage. Compared to haplorhines, little is known about yawning behavior in general in strepsirhine primates. However, a recent study closely examined the context of yawns that 
97

98

99

100

101

102

103

104 105

106

107

108

109

110

111

112

113

114

115

116

117

118

119 occurred among wild ring-tailed lemurs (Lemur catta) and Verreaux's sifakas (Propithecus verreauxi) (Zannella et al. 2015). Like many animals described above, lemurs of both species yawned after events expected to produce anxiety, such as within-group aggressive incidents, encounters with unfamiliar stimuli or attacks by predators (Zanella et al. 2015). These recent findings corroborate previous reports that ring-tailed lemurs occasionally yawn during intergroup encounters (Pereira \& Kappeler 1997; Nunn \& Deaner 2004). In addition to yawning when anxious, both ring-tailed lemurs and sifakas, like other animal species, yawned when they changed behavioral state in relaxed contexts, such as rising from rest to walk to a nearby place (Zannella et al. 2015).

Here, we used a video playback experiment comparable to those used in haplorhines to determine whether contagious yawning occurs in free-ranging, captive ring-tailed lemurs and ruffed lemurs (Varecia variegata) in relaxed settings. Ring-tailed lemurs form large, hierarchical, cohesive social groups (Sauther et al. 1999) while ruffed lemurs live in fission fusion communities (Vasey 2007). Given their complex social systems, these two species are ideal candidates to test whether contagious yawning occurs in strepsirhines.

The evidence for contagious yawning in haplorhines as well as several diverse nonprimate species suggests that the phenomenon is evolutionarily ancient, and would thus appear in strespirhine as well as haplorhine primates. Furthermore, lemurs show evidence of social learning (Stoinski et al. 2011; Kendal et al. 2010) and other forms of complex social cognition (Sandel et al. 2011; MacLean et al. 2013; Bray et al. 2014) suggesting that they likely possess basic empathetic processes. Thus, we expected that both ring-tailed lemurs and ruffed lemurs would demonstrate contagious yawning. 
120

121

122

123

124

125

126

127

128

129

130

131

132

133

134

135

136

137

138

139

140

141

142

143

\section{Methods}

Experiment 1. Video stimulus validation

We modeled our approach after experimental paradigms used in monkeys and apes that rely on video stimuli to test contagious yawning (Anderson et al. 2004; Paulkner \& Anderson 2006; Amici et al. 2014). Many species respond to behaviors presented in videos, and, as lemurs have been shown to make appropriate choices between still onscreen images (MacLean et al. 2008; 2012; Merritt et al. 2007, 2011) and to discern a conspecific's identity from photographs (Marechal et al. 2010) it is likely that lemurs are capable of perceiving individuals on a screen. However, lemurs also heavily rely on olfactory cues to gather social information (e.g. Drea \& Scordato 2007) and no previous study that we are aware of has used video playbacks to induce behavioral responses in lemurs. Thus, we performed experiment 1 to test whether lemurs could meaningfully perceive moving images on a screen.

We exposed lemur subjects to video playbacks for which we expected them to produce differential responses: footage of a predator, and footage of their primary human caretaker. These lemurs occasionally encounter several potential predator species in their free-ranging enclosures, including wild gray foxes (Urocyon cinereoargenteus). Upon seeing these foxes, ruffed lemurs become attentive and emit vocalizations (RBR, pers. obs.). When lemurs see their caretakers, they tend to approach them or do not change their behavior (RBR, pers. obs.).

Study Site and Subjects

For this and the subsequent experiments, we tested lemurs housed at the Duke Lemur Center in Durham, North Carolina, USA. Most social groups consisted of 5 to 10 individuals living in semi free-ranging enclosures with seasonal access to fenced portions of forest as well as indoor and outdoor rooms. Testing took place in indoor rooms, which were connected by doors that experimenters could open and close. Individual room dimensions were $2.2 \times 2.1$ meters and 
144 groups typically had one outdoor and one indoor enclosure per adult individual. Subjects were 145 fed a daily diet of fruit and monkey chow and had access to water ad libitum.

In experiment 1, we tested 28 subjects (ring-tailed lemurs: 7 M, 10 F, 0.7-21 years; ruffed

147 lemurs: 4 M, 7 F, 0.8 -16 years) (Table 1$)$.

148 Apparatus \& Procedure

149 We showed lemurs two silent video clips, both 30 seconds in length. One clip showed 150 footage of a red fox (Vulpes vulpes) walking, and the other, footage of subjects' caretaker 151 presenting a bowl of grapes. Using a Vivitek d510 DLP projector, we projected videos to life152 size dimensions onto a 2.2-meter screen placed outside the mesh of an indoor room. We allowed 153 group members to remain together in the brick-walled room during the video playback. We 154 chose not to isolate individuals because predator response could be mediated by the presence of 155 groupmates and because viewing a predator might be a stressful experience for lemurs. Groups had four total test sessions conducted on separate days, two days to three weeks 157 apart. In each session, the group watched a single video that featured either a fox or their 158 caretaker. Each group spent two sessions watching the fox video and two watching the caretaker 159 video. The order in which subjects watched the videos was counterbalanced between groups. Before starting each video, we scattered dried fruit on the ground at the front of the enclosure to encourage individuals to be on the ground when the video began. We began the playback when

162 all lemurs had finished swallowing and no fruit remained on the ground. As a result of group 163 dominance relationships, certain individuals would not co-feed, and some lemurs remained 164 resting on ledges or supports above the ground when the video started. During test sessions, one experimenter recorded subjects' activities with a handheld 166 camera, while a second experimenter coded behavioral responses. A second camera captured 
167

168

most of the enclosure at a wide angle. We filmed for the duration of the 30 -second video playback and for two subsequent minutes.

An experimenter then coded behavioral responses from video. From these videos we recorded (1) whether subjects moved upward, defined as moving vertically into a new level of the testing room when the room was divided into three levels: lower, middle, and upper, during the 30 -second video, and (2) the alarm vocalizations they made during the video playback and for 1.5 minutes following its conclusion. For ring-tailed lemurs, who may produce alarm "click" or grunt-like vocalizations in response to terrestrial predators (Sauther 1989) we recorded the amount of time in the 2-minute period that grunts were audible from the group. As ring-tailed lemurs do not open their mouths when they produce these grunts, it was impossible to score the vocalizations at the individual level. For ruffed lemurs, we recorded the number of alarm vocalizations made by specific individuals. Vocalizations could be attributed to specific individuals in ruffed lemurs due to the open-mouth postures that accompany vocalizations in this species (Macedonia \& Taylor 1985). These vocalizations included rumbling sounds, often made by one individual, and roars, in which multiple group members typically participated.

A second coder who was blind to the condition and hypothesis coded $20 \%$ of the videos for reliability. Inter-observer reliability was excellent, both for subjects' movement during the trial $($ Cohen's Kappa $=0.92)$, the duration of alarm vocalizations in ring-tailed lemurs $(\mathrm{R}=0.73$, $\mathrm{p}<0.05$ ), and the number of alarm vocalizations in ruffed lemurs, for which agreement was perfect.

\section{Analyses}

We tested the prediction that more upward movement and alarm vocalizations would occur in the fox condition compared to the caretaker condition using Related-Samples Wilcoxon Signed Ranks Tests and adopting a directional hypothesis testing framework following the 
191 conventions $(\delta=0.01, \mathrm{Y}=0.04)$ recommended by Rice and Gaines (1994). Accordingly, the 192 null hypothesis was rejected when the 1-tailed $\mathrm{p}$ value was $\leq .04$ in the predicted direction, or $\geq$ 193.99 in the unanticipated direction.

194 Experiment 2. Contagious Yawning

195 Session 1: Individual Condition

196 Here we explored whether ring-tailed lemurs and ruffed lemurs yawned contagiously by

197 exposing individuals to video projections of yawning conspecifics. To understand whether social

198 bonds and familiarity might affect contagious behaviors (e.g. Campbell \& deWaal 2011), each

199 subject watched footage of a groupmate and footage of a stranger.

200 Subjects:

201

We tested 20 lemurs (ring-tailed lemurs, 3 Male, 7 Female, age range: 1-21 years; ruffed

202 lemurs: 4 Male, 6 Female, age range: 2-22 years) living in four social groups that were housed

203 separately from one another (Table 1).

204 Apparatus \& Procedure:

205 In experiment 2, we showed lemurs experimental and control videos. The projection 206 methods were identical to those in experiment 1. Experimental videos contained footage of a

207 lemur yawning while control videos showed the same individual at rest. We filmed both yawning 208 and control footage when animals were relaxed. All videos contained a 5-second yawning or 209 control clip that was repeated in a looped sequence for a total duration of five minutes. Example

210 frames from these videos are shown in Figure 1. The lemurs featured in these videos were the 211 same sex and of similar age. They were current groupmates of some subjects but strangers to 212 others so that footage shown to one lemur group as a groupmate could be shown to the other 213 lemur group as a stranger, and all subjects of a given species experienced identical stimuli. 
Each subject partook in two testing sessions up to two weeks apart. In each session, subjects watched an experimental (conspecific yawning) and control (conspecific resting) video; in one session, the featured individual was a groupmate, and in the other, a stranger. The order in which subjects watched groupmates and strangers was counterbalanced between subjects, as was the order in which they watched yawning and control stimuli within each of these sessions.

Yawning and control sessions were identical in format. We tested subjects in brickwalled rooms so that they could not view their groupmates, though they could potentially hear them if they vocalized. To attract subjects' attention at the start of each playback, an experimenter tapped lightly on the back of the projector screen. We began each session with a one-minute habituation period during which a solid blue "blank" screen was projected. After this time, we played either the yawning or control video for five minutes. Immediately following the first video, we projected the blank screen for one minute, and then played the second video for five minutes.

One experimenter live-coded the number of yawns that occurred in each video condition while a second experimenter recorded the subject with a handheld video camera that was focused on the subject's face as the subject moved freely within the test room. Another camera captured the enclosure and subject in its entirety. A second coder who was blind to the test condition and to the hypothesis of the experiment watched $20 \%$ of the videos and coded them for reliability. Inter-observer reliability was perfect.

\section{Session 2. Group Context}

In a second experimental session, lemurs watched videos in a group. It may be that social context is an important component of behavioral contagion, and a solitary context is insufficient to stimulate contagious yawning, as some studies that identified contagious yawning in haplorhine primates tested subjects simultaneously in a group setting (e.g., Paulkner and 
238 Anderson 2006). To understand whether a group context might enhance, or allow for behavioral

239 contagion in lemurs, we exposed subjects to the yawning and control videos they had watched in

240 experiment 1, but this time, we presented the videos to the entire group.

241 Subjects

242

We tested 24 lemurs (ring-tailed lemurs: 7 M, 10 F, 0.7-21 years; ruffed lemurs: 4 M, 7 F, 2431 -16 years) in experiment 2 , most of whom had participated in session 1 (Table 1 ). Certain

244 individuals from session 1, who had been moved from the DLC, or integrated into new social 245 groups within the DLC, were not able to participate in session 2. In addition, some lemurs who 246 had been too young to be isolated in session 1 could participate in session 2 .

Eight months elapsed between the end of session 1 and start of session 2 . The stimuli and presentation methods for session 2 were identical to those of session 1, except that in session 2 , subjects of the four study groups watched the videos with all of their group members present, 250 including individuals who were featured in stimuli videos.

252 footage of a groupmate and one in which they watched yawning and control footage of a 253 stranger. The order in which we showed yawning and control footage was counterbalanced 254 between groups within species. The order in which groups watched groupmate and stranger 255 videos was also counterbalanced between groups.

257 the identities of the yawners. A second coder who was blind to the test condition and to the 258 hypothesis of the experiment coded $20 \%$ of session videos for reliability. Inter-observer 259 reliability was perfect. 


\section{Results}

262 Experiment 1. Video stimulus validation

263 Across species, individuals moved to a higher location in the enclosure more often in the

264 fox condition than in the caretaker condition $(n=28, Z=-2.89 p<0.01)$ (Figure 2). The same

265 analysis within each species revealed that ring-tailed lemurs, but not ruffed lemurs showed a

266 pattern to move upwards more often during the fox than the caretaker video (ring-tailed lemurs:

$267 \mathrm{n}=17, \mathrm{Z}=-3.00 \mathrm{p}<0.01$; ruffed lemurs: $\mathrm{n}=11, \mathrm{Z}=-0.58 \mathrm{p}=0.28$ ). This is possibly because more

268 ring-tailed lemur than ruffed lemur individuals began watching the video from the ground.

269 Ring-tailed lemurs spent more time alarm grunting in the fox condition than in the

270 caretaker condition, grunting, on average, for $58 \pm 48.8$ seconds in the fox condition compared to

$27117 \pm 18.4$ seconds in the caretaker condition. Ruffed lemurs also made significantly more alarm

272 vocalizations in the fox condition than in the caretaker condition $(n=11, Z=-2.39, p=0.01)$

273 (Figure 3). Only one individual vocalized in the caretaker condition. There were a total of 30

274 alarm vocalizations in the fox condition, with an average of $2.73 \pm 5.0$ calls per individual, and a

275 total of three alarm vocalizations in the caretaker condition, with an average of $0.27 \pm 0.91$ calls

276 per individual.

277 Experiment 2. Contagious Yawning

278 In the individual yawning sessions, only one yawn occurred across all 20 individuals in

279 all four conditions. An adult female ruffed lemur yawned once in the stranger yawning condition.

280 In group yawning sessions, only two yawns occurred across all 24 individuals in all four

281 conditions. Two ruffed lemurs each yawned once during the stranger yawning condition (Figure

$2824)$. 


\section{Discussion}

Lemurs did not yawn contagiously in response to videos of yawning groupmates or strangers. Our findings are consistent across individual and group contexts, with large samples, and between two of the most socially complex strepsirhine species. However, lemurs did demonstrate that they respond meaningfully to video footage in general; they moved upward and made alarm calls while viewing footage of a predator but not a caretaker. This study provides the first evidence that lemurs do not respond to yawning video stimuli in the same way as haplorine primates, and suggests the possibility that strepsirhines do not yawn contagiously. Given that many social animals, including wolves and budgerigars in addition to haplorhine primates, yawn contagiously with conspecifics, it seems surprising that lemurs did not do so. However, several aspects of interindividual social relationships in lemurs differ in relevant ways from those of haplorhines and other social mammals. First, even lemurs species that live in large social groups appear to engage in fewer cooperative activities than haplorhines and are characterized by more within-group competition (for review, see: Fichtel \& Kappeler 2010). For example, ring-tailed lemurs form matrilineal groups where females, like female Old World monkeys, affiliate most often with kin, grooming with them and maintaining close spatial proximity to them frequently. Despite the similarities of these affiliative kin behaviors, ringtailed lemurs, unlike Old World monkeys, rarely recruit or assist others in coalitionary aggression. Ring-tailed lemur mothers rarely support even their daughters in fights (less than 5 percent of the time, Nakamichi \& Koyama 1997). Consequently, ring-tailed lemur daughters, unlike Old World monkey daughters, do not always rank immediately below their mothers (Nakamichi \& Koyama 1997). The absence of such alliances in lemurs contrasts not only to certain Old World monkeys, but to many social mammals who form coalitions against others, including chimpanzees and wolves discussed above (for review, see: Harcourt \& DeWaal 1992). 
In addition to a lack of alliances, lemurs show minimal post-conflict affiliation with other individuals (Fichtell \& Kappeler 2010). After aggressive conflicts, individuals of a wide range of species show increased affiliation with their former opponents or with other groupmates, including baboons (Castles \& Whiten 1998), long-tailed macaques (Aureli \& van Schaik 1991), chimpanzees (DeWaal \& van Roosmalen 1979), dolphins (Tamaki et al. 2006), rooks (Seed et al. 2007), domestic horses (Cozzi et al. 2010), goats (Schino 1998), hyenas (Hofer \& East 2000), dogs (Cools et al. 2008), and wolves (Cordoni \& Palagi 2008). This affiliation is thought to reduce anxiety and future aggression (e.g. Castles \& Whiten 1998) and has implications for group cohesion.

Several captive studies have examined post-conflict affiliation in ring-tailed lemurs specifically. One study found no evidence for affiliation in the 10 minutes following a conflict, a typical time length examined in species above (Kappeler 1993), but a follow-up study on the same group observed opponents for 70 minutes post-conflict and found that more affiliation occurred in post-conflict periods compared to control periods (Rolland \& Roeder 2000). A later study reexamined post-conflict association in ring-tailed lemurs at the dyadic level with a larger sample size and found that breeding seasonality may influence the behavior: pairs of ring-tailed lemurs showed increased affiliation after a conflict in the social group with breeding females but not in the social group with lactating females who are less likely to be tolerant of males (Palagi et al. 2005). Other lemur species, including redfronted brown lemurs and Verreaux's sifakas do show some post-conflict affiliation (Kappeler 1993; Palagi et al. 2008). Post-conflict association has not to our knowledge been studied in ruffed lemurs, but like ring-tailed lemurs, this species also experiences seasonal shifts in social behavior (Vasey 2009).

Given these peculiarities of lemur social social relationships, one interpretation of our 
331 main result is that contagious yawning capabilities evolved in haplorhine primates after the

332 lineage split from strepsirhines and that the phenomenon seen in other distantly related

333 vertebrates like budgies and wolves is the result of convergent evolution linked to the social

334 relationships between individuals in these species; budgeriars form cohesive flocks and wolves

335 are obligate carnivores that acquire food by hunting cooperatively with groupmates (Wyndham

336 1980; Peterson \& Ciucci 2003). Another possibility is that contagious yawning occurred at very

337 low levels in a primate ancestor and became exaggerated as the result of selection in some social

338 species and not others. In our study, yawns occurred infrequently, but importantly, they occurred

339 exclusively in conditions where lemurs watched yawning stimuli. Although this evidence

340 certainly does not suggest contagious yawning is a strong phenomenon in lemurs, it is consistent

341 with the possibility that contagious yawning is evolutionarily ancient but has evolved to be more

342 prevalent and easily elicitied in haplorhines and other social species, but not in ring-tailed or

343 ruffed lemurs.

An alternative explanation for our results is that lemurs do yawn contagiously but that

345 visual stimuli alone are not sufficient to induce such behavior. Some research suggests that this is

346 the case for pet dogs. Joly-Mascheroni and colleagues (2008) found that 72 percent of dogs

347 tested yawned contagiously in response to a live human who yawned, but in a later study Harr

348 and colleagues (2009) showed 15 dogs video footage of unfamiliar dogs and humans yawning

349 and only one subject yawned contagiously. Video was insufficient to produce contagious

350 yawning in dogs. Yet, dogs, like lemurs in this study, do produce responses to video in other

351 contexts. For instance, dogs pay attention to a familiar human's communicative cues that occur

352 onscreen (Pongracz et al. 2003). This suggests that dogs can perceive and respond to the content

353 of videos, but that a contagious yawning response requires additional cues. For instance, Silva 
354

355

and colleagues (2012) found that auditory cues were integral to the contagious yawning response in dogs; auditory playbacks of humans yawning alone caused dogs to contagiously yawn.

Like pet dogs, lemurs may produce some but not all natural behaviors in response to video alone, but require other cues, not conveyed in video, to yawn contagiously. Our videos did not include sounds and it is possible that auditory cues are important for contagious yawning in lemurs. However, unlike dog yawns, lemur yawns are silent to human observers and solely visual playbacks did induce yawning in apes and in stumptail macaques (e.g. Anderson et al. 2004; Paulkner \& Anderson 2006), though visual stimuli are perhaps relatively more salient to haplorhine compared to strepsirhine primates who use olfaction to communicate important social information (e.g. Scordato \& Drea 2007). Olfactory cues can induce yawning in rodents (Moyaho et al. 2015) and lemurs sometimes yawn when presented with sticks scent-marked by other lemurs (Sandel, pers. comm.), though, importantly, these yawn responses do not occur in response to the yawns of groupmates and likely represent phenomena different than empathyrelated contagious yawning investigated here. Issues of the importance of auditory, olfactory, and other cues in potentially inducing contagious yawning in lemurs could be informed through an observational study of yawning in lemur social groups.

We hope this study will be the first of many that explore across a range of species the distribution of contagious yawning in order to understand its phylogenetic origin and ultimate function (MacLean et al. 2012).

\section{Ethical approval}

All applicable international, national, and/or institutional guidelines for the care and use of animals were followed. All procedures performed in studies involving animals were in 
377 accordance with the ethical standards of the Institutional Animal Care and Use Committee at 378 Duke University (Protocol \# A199-11-08).

379

380

381

382

383

384

385

386

387

388

389

390

391

392

393

394

395

396

397

398

399

400

401

\section{References}

Altmann SA (1967) The structure of primate social communication. Social communication among primates:325-362

Amici F, Aureli F, Call J (2014) Response facilitation in the four great apes: is there a role for empathy? Primates 55:113-118 doi:10.1007/s10329-013-0375-1

Anderson JR, Myowa-Yamakoshi M, Matsuzawa T (2004) Contagious yawning in chimpanzees Proceedings of the Royal Society of London B: Biological Sciences 271:S468-S470

Aureli F, van Schaik CP (1991) Post-conflcit behaviour in long tailed macaques (Macaca fascicularis): II. coping with the uncertainty. Ethology 89: 101-114

Baenninger R (1997) On yawning and its functions Psychonomic bulletin \& review 4:198-207

Baker KC, Aureli F (1997) Behavioural indicators of anxiety: an empirical test in chimpanzees Behaviour 134:1031-1050

Bray J, Krupenye C, Hare B (2014) Ring-tailed lemurs (Lemur catta) exploit information about what others can see but not what they can hear Animal cognition 17:735-744

Campbell MW, De Waal FB (2011) Ingroup-outgroup bias in contagious yawning by chimpanzees supports link to empathy PloS one 6:e18283

Campbell MW, de Waal FB (2014) Chimpanzees empathize with group mates and humans, but not with baboons or unfamiliar chimpanzees Proc Biol Sci 281:20140013 doi:10.1098/rspb.2014.0013

Castles DL, Whiten A (1998) Post-conflict behaviour of wild olive baboons: Stress and selfdirected behaviour. Ethology 104: 148-160

Cools AK, Van Hout AJM, Nelissen MH (2008). Canine Reconciliation and Third-PartyInitiated Postconflict Affiliation: Do Peacemaking Social Mechanisms in Dogs Rival 
402

403

404

405

406

407

408

409

410

411

412

413

414

415

416

417

418

419

420

421

422

423

424

425

Those of Higher Primates? Ethology114: 53-63

Cozzi A, Sighieri C, Gazzano A, Nicol CJ, Baragli P (2010) Post-conflict friendly reunion in a permanent group of horses (Equus caballus).Behavioural processes 85: 185-190

de Waal FB (2008) Putting the altruism back into altruism: the evolution of empathy Annu Rev Psychol 59:279-300 doi:10.1146/annurev.psych.59.103006.093625

De Waal FBM, van Roosmalen A (1979) Reconciliation and consolation among chimpanzees. Behav. Ecol. Sociobiol 5: 55-66

Demuru E, Palagi E (2012) In bonobos yawn contagion is higher among kin and friends PLoS One 7:e49613 doi:10.1371/journal.pone.0049613

Drea CM, Scordato ES (2008) Olfactory communication in the ringtailed lemur (Lemur catta): form and function of multimodal signals. In: Chemical Signals in Vertebrates 11. Springer, pp 91-102

Fichtel C, Kappeler PM (2010) Human universals and primate symplesiomorphies: establishing the lemur baseline. In Mind the Gap (pp. 395-426). Springer Berlin Heidelberg

Gallup AC (2011) Why do we yawn? Primitive versus derived features Neuroscience \& Biobehavioral Reviews 35:765-769

Harcourt AH, DeWaal FB (1992). Coalitions and alliances in humans and other animals. Oxford University Press.

Harr AL, Gilbert VR, Phillips KA (2009) Do dogs (Canis familiaris) show contagious yawning? Anim Cogn 12:833-837 doi:10.1007/s10071-009-0233-0

Harr AL, Gilbert VR, Phillips KA (2009) Do dogs (Canis familiaris) show contagious yawning? Animal cognition 12:833-837

Hofer H, East ML (2000). Conflict management in female-dominated spotted hyenas. In Natural Conflict Resolution, F Aureli and F de Waal, eds. Berkeley: University of California Press: pp. 232-234. 
Joly-Mascheroni RM, Senju A, Shepherd AJ (2008) Dogs catch human yawns Biology Letters 4:446448

Kappeler PM (1993) Reconciliation and post-conflict behaviour in ringtailed lemurs, Lemur catta and redfronted lemurs, Eulemur fulvus rufus. Animal Behaviour 45: 901-915

Kendal RL, Custance DM, Kendal JR, Vale G, Stoinski TS, Rakotomalala NL, Rasamimanana H (2010) Evidence for social learning in wild lemurs (Lemur catta) Learning \& Behavior 38:220-234

Kutsukake N, Clutton-Brock TH (2008) Do meerkats engage in conflict management following aggression? Reconciliation, submission and avoidance. Animal Behaviour 75::1441-53

Leone A, Ferrari PF, Palagi E (2014). Different yawns, different functions? Testing social hypotheses on spontaneous yawning in Theropithecus gelada. Scientific reports 4.

Lund JD, Jørgensen MC (1999) Behaviour patterns and time course of activity in dogs with separation problems Applied Animal Behaviour Science 63:219-236

Macedonia JM, Taylor LL (1985) Subspecific divergence in a loud call of the ruffed lemur (Varecia variegata) American Journal of Primatology 9:295-304

MacLean EL et al. (2012) How does cognition evolve? Phylogenetic comparative psychology Animal cognition 15:223-238

MacLean EL et al. (2014) The evolution of self-control Proceedings of the National Academy of Sciences 111:E2140-E2148

MacLean EL, Mandalaywala TM, Brannon EM (2012) Variance-sensitive choice in lemurs: constancy trumps quantity Animal cognition 15:15-25

MacLean EL, Merritt DJ, Brannon EM (2008) Social complexity predicts transitive reasoning in prosimian primates Animal behaviour 76:479-486

Marechal L, Genty E, Roeder JJ (2010) Recognition of faces of known individuals in two lemur species (Eulemur fulvus and E. macaco) Animal Behaviour 79:1157-1163 
450

451

452 453

454

455

456

457

458

459

460

461

462

463

464

465

466

467

468

469

470

471

472

473

Merritt D, Maclean EL, Jaffe S, Brannon EM (2007) A comparative analysis of serial ordering in ringtailed lemurs (Lemur catta) J Comp Psychol 121:363-371 doi:10.1037/0735-7036.121.4.363

Merritt DJ, Maclean EL, Crawford JC, Brannon EM (2011) Numerical rule-learning in ring-tailed lemurs (Lemur catta) Front Psychol 2:23 doi:10.3389/fpsyg.2011.00023

Miller ML, Gallup AC, Vogel AR, Vicario SM, Clark AB (2012) Evidence for contagious behaviors in budgerigars (Melopsittacus undulatus): an observational study of yawning and stretching Behav Processes 89:264-270 doi:10.1016/j.beproc.2011.12.012

Moyaho A, Rivas-Zamudio X, Ugarte A, Eguibar JR, Valencia J (2015) Smell facilitates auditory contagious yawning in stranger rats Animal cognition 18:279-290

Nakamichi M, Koyama N (1997) Social relationships among ring-tailed lemurs (Lemur catta) in two free-ranging troops at Berenty Reserve, Madagascar. International Journal of Primatology 18(1): 73-93

Norscia I, Palagi E (2011) Yawn contagion and empathy in Homo sapiens PLoS One 6:e28472 doi:10.1371/journal.pone.0028472

Nunn CL, Deaner RO (2004) Patterns of participation and free riding in territorial conflicts among ringtailed lemurs (Lemur catta) Behavioral Ecology and Sociobiology 57:50-61 doi:10.1007/s00265-004-0830-5

O'Hara SJ, Reeve AV (2011) A test of the yawning contagion and emotional connectedness hypothesis in dogs, Canis familiaris Animal Behaviour 81:335-340

Palagi E, Antonacci D, Norscia I (2008) Peacemaking on treetops: first evidence of reconciliation from a wild prosimian (Propithecus verreauxi) Animal Behaviour 76: 737-747

Palagi E, Leone A, Mancini G, Ferrari P (2009) Contagious yawning in gelada baboons as a possible expression of empathy Proceedings of the National Academy of Sciences 106:19262-19267

Palagi E, Norscia I, Demuru E (2014) Yawn contagion in humans and bonobos: emotional affinity 
matters more than species PeerJ 2:e519 doi:10.7717/peerj.519

Palagi E, Paoli T, Tarli SB (2005) Aggression and reconciliation in two captive groups of Lemur catta. International Journal of Primatology 26: 279-294

Paukner A, Anderson JR (2006) Video-induced yawning in stumptail macaques (Macaca arctoides) Biol Lett 2:36-38 doi:10.1098/rsbl.2005.0411

Pereira ME, Kappeler PM (1997) Divergent systems of agonistic behaviour in lemurid primates Behaviour 134:225-274

Peterson RO, Ciucci P (2003) The wolf as a carnivore Wolves: behavior, ecology, and conservation: $104-130$

Platek SM, Critton SR, Myers TE, Gallup GG (2003) Contagious yawning: the role of self-awareness and mental state attribution Cognitive Brain Research 17:223-227 doi:10.1016/s09266410(03)00109-5

Pongrácz P, Miklósi Á, Dóka A, Csányi V (2003) Successful Application of Video-Projected Human Images for Signalling to Dogs Ethology 109:809-821

Provine RR (1986) Yawning as a stereotyped action pattern and releasing stimulus Ethology 72:109-122

Rice WR, Gaines SD (1994) Heads I win, tails you lose': testing directional alternative hypotheses in ecological and evolutionary research Trends in Ecology and Evolution 9:235-236

Rolland N, Roeder JJ (2000) Do ringtailed lemurs (Lemur catta) reconcile in the hour postconflict?: a pilot study. Primates 41: 223-227

Romero T, Ito M, Saito A, Hasegawa T (2014) Social modulation of contagious yawning in wolves

Romero T, Konno A, Hasegawa T (2013) Familiarity bias and physiological responses in contagious yawning by dogs support link to empathy PLoS One 8:e71365 doi:10.1371/journal.pone.0071365

Sandel AA, MacLean EL, Hare B (2011) Evidence from four lemur species that ringtailed lemur social 
cognition converges with that of haplorhine primates Animal Behaviour 81:925-931

Sauther ML (1989) Antipredator behavior in troops of free-rangingLemur catta at Beza Mahafaly Special Reserve, Madagascar International Journal of Primatology 10:595-606

Sauther ML, Sussman RW, Gould L (1999) The socioecology of the ringtailed lemur: thirty-five years of research Evolutionary Anthropology Issues News and Reviews 8:120-132

Seed AM, Clayton NS, Emery NJ (2007) Postconflict third-party affiliation in rooks, Corvus frugilegus. Current Biology 17: 152-158

Senju A, Maeda M, Kikuchi Y, Hasegawa T, Tojo Y, Osanai H (2007) Absence of contagious yawning in children with autism spectrum disorder Biol Lett 3:706-708 doi:10.1098/rsbl.2007.0337

Seyfarth RM, Cheney DL (2013) Affiliation, empathy, and the origins of theory of mind Proceedings of the National Academy of Sciences 110:10349-10356

Silva K, Bessa J, de Sousa L (2012) Auditory contagious yawning in domestic dogs (Canis familiaris): first evidence for social modulation Animal cognition 15:721-724

Smith E (1999) Yawning: an evolutionary perspective Human evolution 14:191-198

Stoinski T, Drayton L, Price E (2011) Evidence of social learning in black-and-white ruffed lemurs (Varecia variegata) Biology letters 7:376-379

Tamaki N, Morisaka T, Taki M (2006). Does body contact contribute towards repairing relationships?: The association between flipper-rubbing and aggressive behavior in captive bottlenose dolphins. Behavioural processes, 73: 209-215

Vasey N (2007) Impact of seasonality and reproduction on social structure, ranging patterns, and fission-fusion social organization in red ruffed lemurs. In: Lemurs. Springer, pp 275-304 Wyndham E (1980) Diurnal cycle, behaviour and social organization of the Budgerigar Melopsittacus undulatus Emu 80:25-33 
521 Zannella A, Norscia I, Stanyon R, Palagi E (2015) Testing yawning hypotheses in wild

522 populations of two strepsirrhine species: Propithecus verreauxi and Lemur catta Am J Primatol

$523 \quad 77: 1207-1215$ doi:10.1002/ajp.22459

524

525 Figure Captions

526 Table 1. Lemur subjects in all experiments.

527 Figure 1. Frames from yawning stimuli video (left) and control stimuli video (right) of ruffed

528 lemurs (top) and ring-tailed lemurs (bottom).

529 Figure 2. Average number of individuals to move up while watching predator video footage and

530 caretaker video footage in experiment $2(n=28)$

531 Figure 3. Average number of alarm calls per individual ruffed lemurs $(n=11)$ while watching

532 predator and caretaker video footage in experiment 2.

533 Figure 4. Number of individuals who yawned in individual and group contexts in experiment 2.

534

535

536

537

538

539

540

541

542

543

544

545 


\begin{tabular}{|c|c|c|c|c|c|c|c|}
\hline Group & Subject & Species & Sex & $\begin{array}{l}\text { Age } \\
\text { (years) }\end{array}$ & S 1 & S 2 & E 2 \\
\hline 1 & Pyxis & Vv. rubra & $F$ & 17 & $\mathrm{X}$ & $\mathrm{X}$ & $X$ \\
\hline 1 & Hunter & Vv. rubra & $\mathrm{M}$ & 16 & $\mathrm{X}$ & $X$ & $X$ \\
\hline 1 & Scorpius & Vv. rubra & $\mathrm{M}$ & 5 & $\mathrm{X}$ & $\mathrm{X}$ & $X$ \\
\hline 1 & Aries & Vv. rubra & $\mathrm{M}$ & 5 & $\mathrm{X}$ & $\mathrm{X}$ & $X$ \\
\hline 1 & Esther & Vv. rubra & $F$ & 3 & $X$ & $X$ & $X$ \\
\hline 1 & Orion & Vv. rubra & $\mathrm{M}$ & 3 & & & $X$ \\
\hline 1 & Phoebe & Vv. rubra & $F$ & 3 & $X$ & $X$ & $X$ \\
\hline 2 & Carina & Vv. rubra & $\mathrm{F}$ & 8 & $\mathrm{X}$ & $X$ & $X$ \\
\hline 2 & Alphard & V. v. rubra & $\mathrm{M}$ & 23 & $X$ & & \\
\hline 2 & Avior & Vv. rubra & $\mathrm{M}$ & 4 & & & $X$ \\
\hline 2 & Hydra & V.v. rubra & $\mathrm{F}$ & 4 & $X$ & & \\
\hline 2 & Lyra & Vv. rubra & F & 4 & $X$ & $X$ & $X$ \\
\hline 2 & Pandora & Vv. rubra & $\mathrm{F}$ & $<1$ & & $X$ & $X$ \\
\hline 2 & Cordelia & Vv. rubra & $F$ & $<1$ & & $X$ & $\mathrm{X}$ \\
\hline 3 & Schroeder & L. catta & $F$ & 20 & $\mathrm{X}$ & $\mathrm{X}$ & $\mathrm{X}$ \\
\hline 3 & Edelweiss & L. catta & $F$ & 2 & $\mathrm{X}$ & & \\
\hline 3 & Liesl & L. catta & $\mathrm{F}$ & 4 & $\mathrm{X}$ & $\mathrm{X}$ & $\mathrm{X}$ \\
\hline 3 & Aracus & L. catta & $\mathrm{M}$ & 21 & $\mathrm{X}$ & $\mathrm{X}$ & $\mathrm{X}$ \\
\hline 3 & Johan & L. catta & $\mathrm{M}$ & 2 & & & $X$ \\
\hline 3 & Rolfe & L. catta & $\mathrm{M}$ & 1 & $X$ & $X$ & $X$ \\
\hline 3 & Brigitta & L. catta & $\mathrm{F}$ & 1 & & $X$ & $X$ \\
\hline 3 & Gretl & L. catta & $\bar{F}$ & $<1$ & & $X$ & $X$ \\
\hline 4 & Sprite & L. catta & $\mathrm{F}$ & 11 & & $X$ & $X$ \\
\hline 4 & Ginger & L. catta & $\mathrm{F}$ & 6 & $X$ & $X$ & $X$ \\
\hline 4 & Randy & L. catta & $\mathrm{M}$ & 6 & $X$ & $X$ & $\mathrm{X}$ \\
\hline 4 & Schweppes & L. catta & $\mathrm{M}$ & 2 & & & $X$ \\
\hline
\end{tabular}




\begin{tabular}{|r|l|l|l|l|l|l|l|}
\hline $\mathbf{4}$ & Sobe & L. catta & F & 1 & & X & X \\
\hline $\mathbf{4}$ & Sarsparilla & L. catta & F & 1 & & X & X \\
\hline $\mathbf{4}$ & Crystal Light & L. catta & F & 2 & X & & \\
\hline $\mathbf{4}$ & Canada Dry & L. catta & F & 1 & X & X & X \\
\hline $\mathbf{4}$ & Izze & L. catta & F & $<1$ & & $\mathrm{X}$ & $\mathrm{X}$ \\
\hline $\mathbf{4}$ & Jones & L. catta & $\mathrm{M}$ & $<1$ & & $\mathrm{X}$ & $\mathrm{X}$ \\
\hline $\mathbf{4}$ & Stewart & L. catta & $\mathrm{M}$ & $<1$ & & $\mathrm{X}$ & $\mathrm{X}$ \\
\hline
\end{tabular}


546 Figure 1.

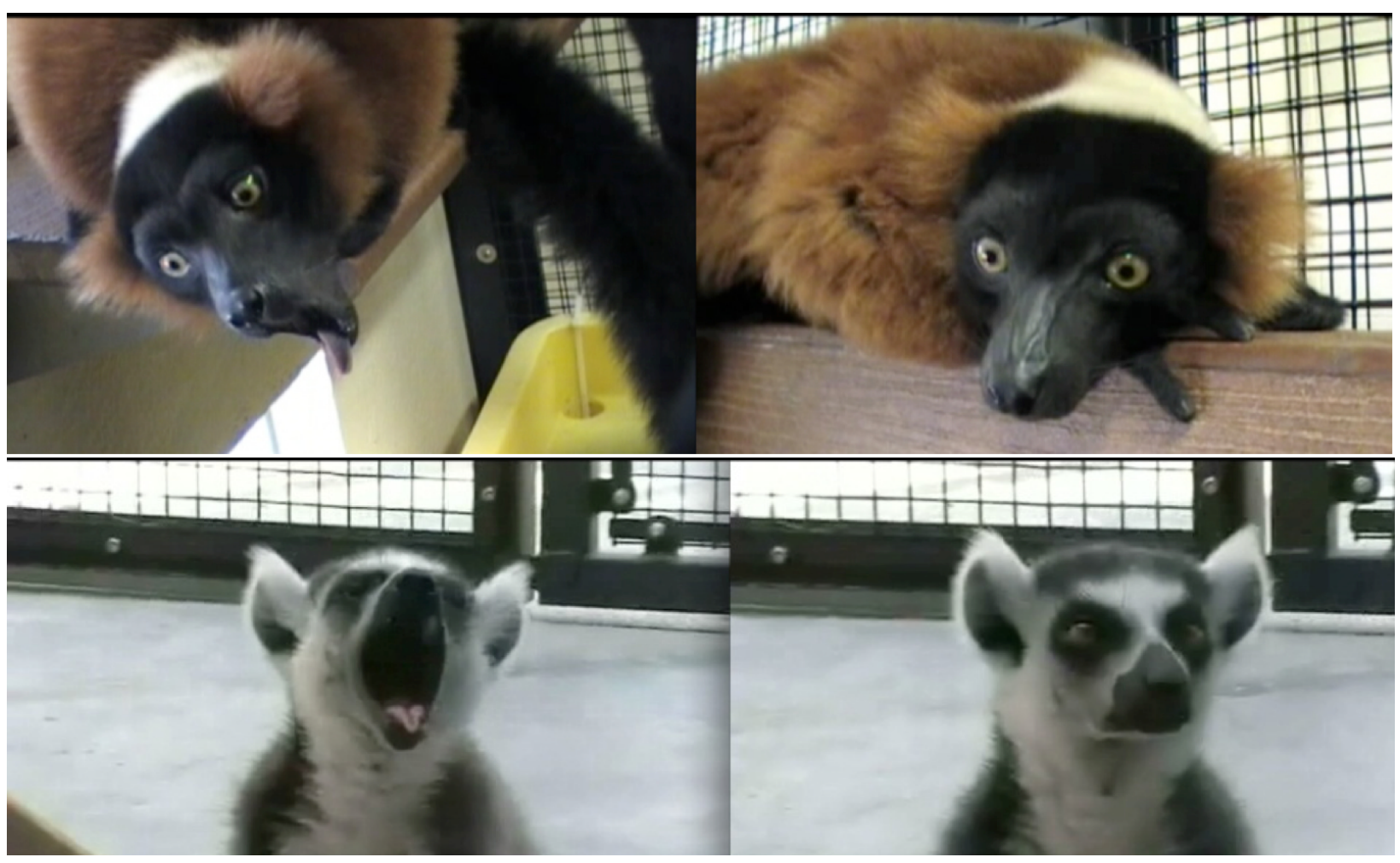


547 Figure 2.

548

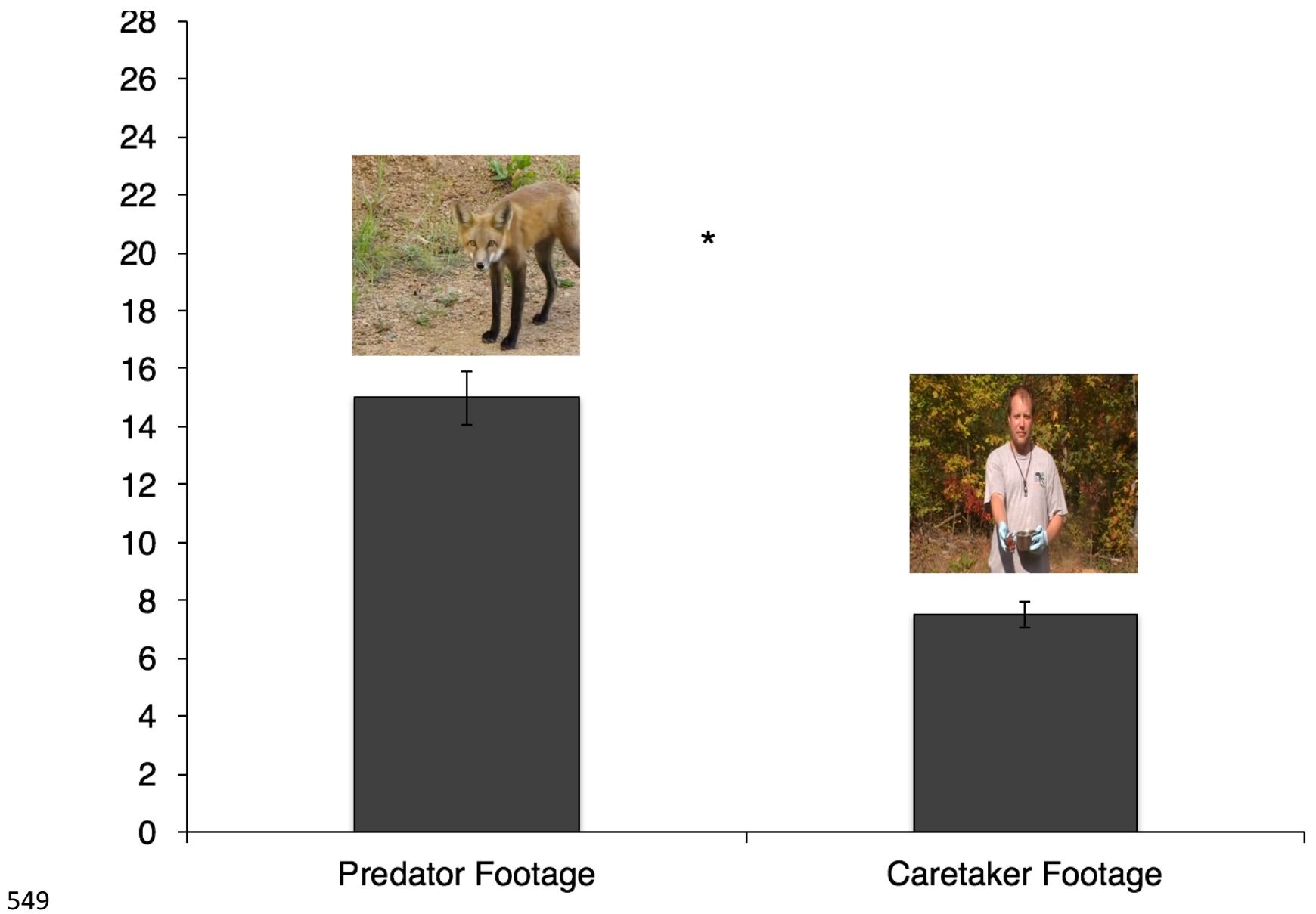

550 
551 Figure 3.

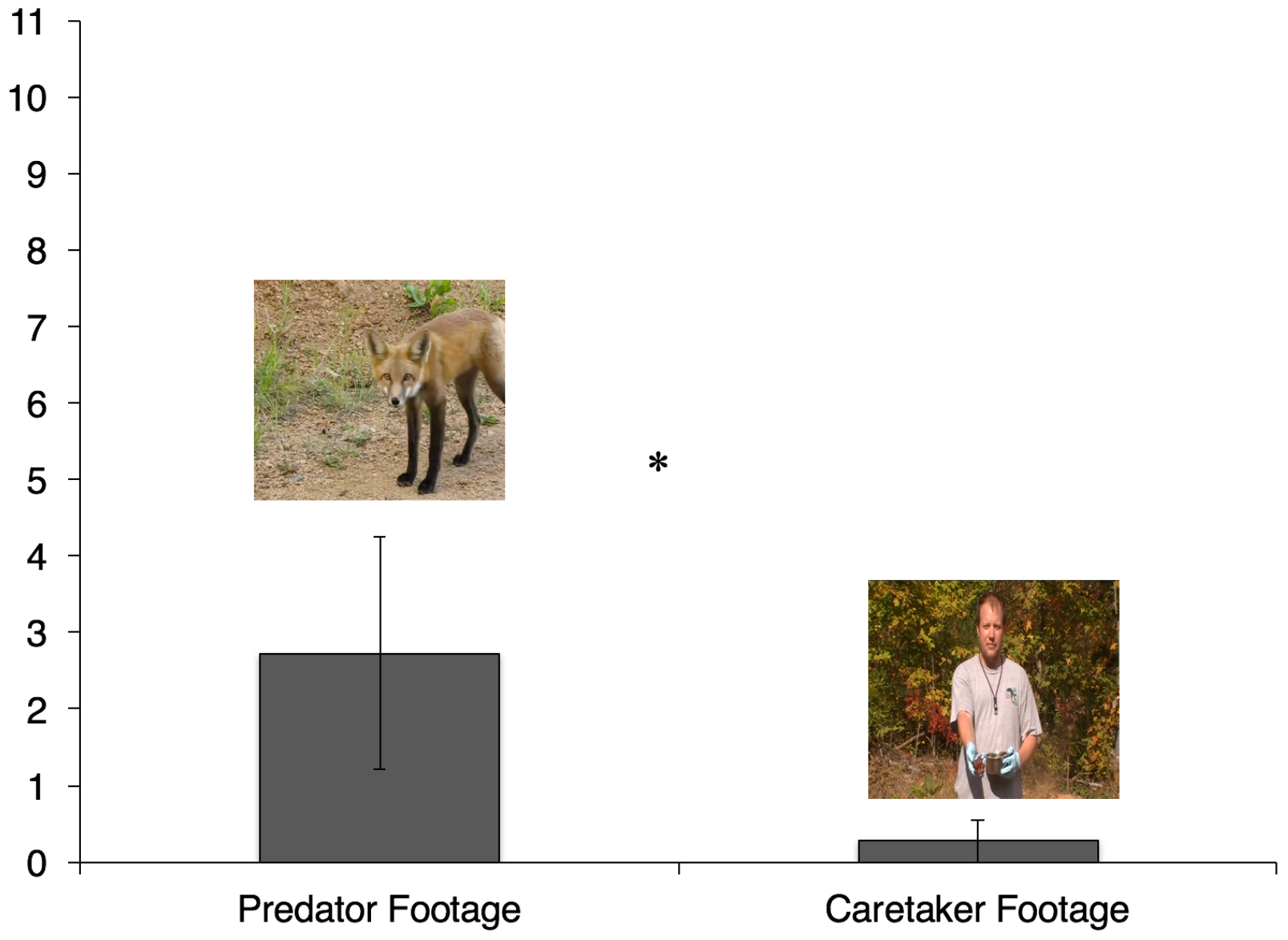

552

553 
554 Figure 4.

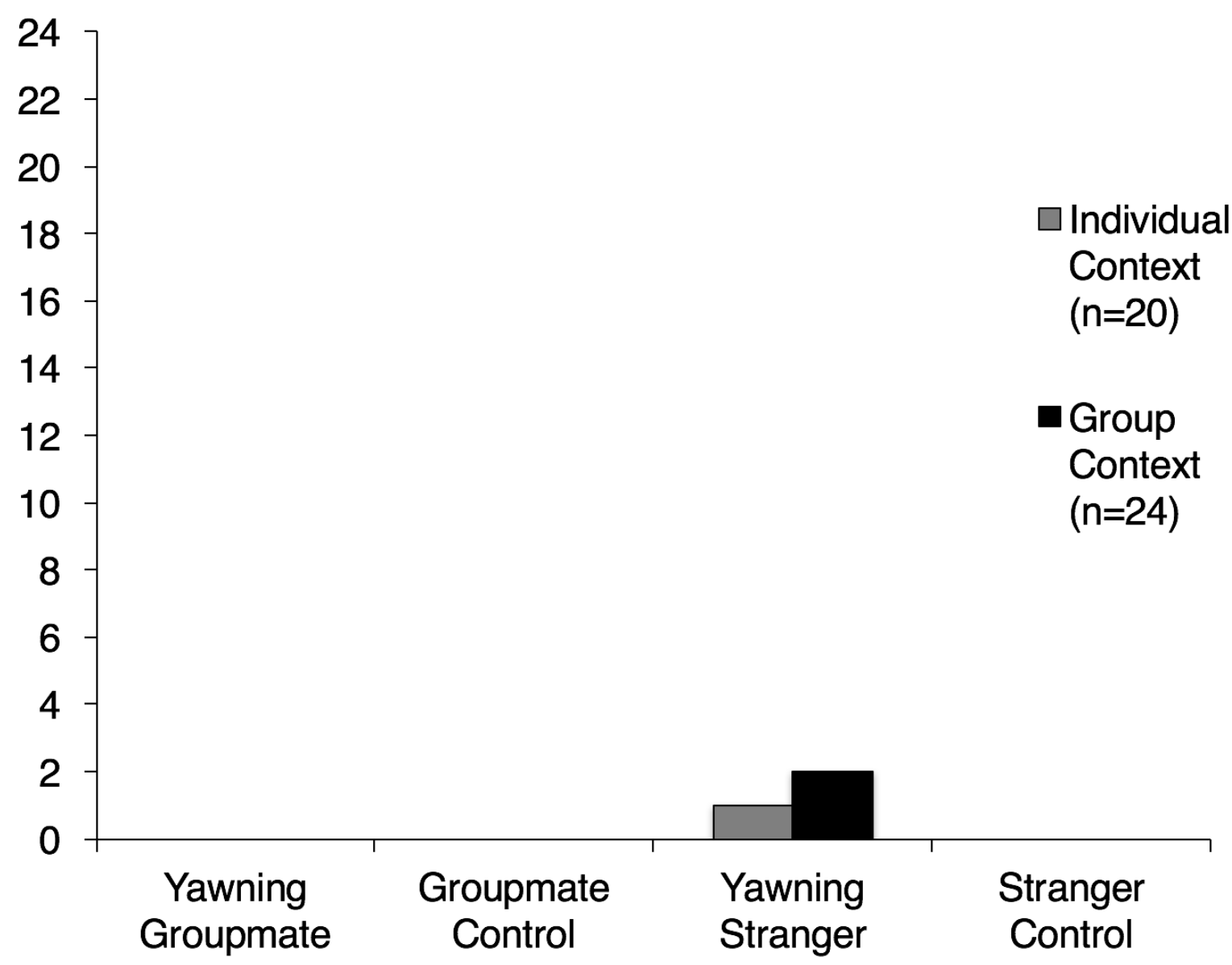

555 